\title{
The contribution of hyperspectral remote sensing to identify vegetation characteristics necessary to assess the fate of Persistent Organic Pollutants (POPs) in the environment
}

\author{
Mirco Boschetti $\left({ }^{1}\right)$, Pietro Alessandro Brivio $\left({ }^{1}\right)$, Daniela Carnesale $\left({ }^{1}\right)$ and Antonio Di Guardo $\left({ }^{2}\right)$ \\ (1) Istituto per il Rilevamento Elettromagnetico dell'Ambiente (IREA), CNR, Milano, Italy \\ ${ }^{(}{ }^{2}$ Dipartimento di Scienze Chimiche ed Ambientali, Università degli Studi dell'Insubria, Varese, Italy
}

\begin{abstract}
During recent years hyperspectral remote sensing data were successfully used to characterise the state and properties of vegetation. The information on vegetation cover and status is useful for a range of environmental modelling studies. Recent works devoted to the understanding of the fate of Persistent Organic Pollutants (POPs) in the environment showed that forests and vegetation in general act as a «sponge» for chemicals present in air and the intensity of this «capture» effect depends on some vegetation parameters such as surface area, leaf composition, turnover etc. In the framework of the DARFEM experiment conducted in late June 2001, different airborne hyperspectral images were acquired and analysed to derive some vegetation parameters of relevance for multimedia models, such as the spatial distribution of plant species and their relative foliage biomass. The study area, south west of Milan, encompasses a range of land cover types typical of Northern Italy, including intensive poplar plantations and natural broad-leaf forest. An intensive field campaign was accomplished during the aerial survey to collect vegetation parameters and radiometric measurements. Results obtained from the analysis of hyperspectral images, map of vegetation species, Leaf Area Index (LAI) and foliage biomass are presented and discussed.
\end{abstract}

Key words hyperspectral imaging - species distribution - LAI - semi-empirical model - POPs

\section{Introduction}

The study and understanding of the fate of Persistent Organic Pollutants (POPs) in the environment is nowadays necessary to manage their risk of adverse effect to humans or to the

Mailing address: Dr. Mirco Boschetti, Istituto per il Rilevamento Elettromagnetico dell'Ambiente (IREA), CNR, Via Bassini 15, 20133 Milano (Italy); e-mail: boschetti.m@irea.cnr.it ecosystem (Mackay et al., 1996). POPs are generally able to be bioaccumulated in the food chain and affect living organisms due to their long persistence and toxicity. Recent publications showed that forests play a key role in the environmental distribution of POPs, since they act as filters of these chemicals, trapping them in the air compartment and transferring to forest soils consequently decreasing their atmospheric half-lives (McLachlan and Horstmann, 1998). Therefore it is necessary to include the vegetation compartment in multimedia models, to understand and predict the fate of these substances in the environment.

Many persistent organic pollutants are known as global contaminants because they have been 
detected in air, water, vegetation and fauna of the most remote pristine regions reached by a longrange transport process. These compounds are semi-volatile and therefore able to volatilize from soils and move through the atmosphere towards areas which can be considerably far away from the sources. PCBs (polychlorobiphenyls), DDTs, HCHs (hexachlorocyclohexanes), PCDDs/Fs (dioxins and furans) are in fact characterized by a low water solubility and low degradability in the environment. Their low solubility results in higher affinity for the organic phases such as organisms or organic carbon rich phases such as vegetation.

Recently much attention has focused on the understanding of the global cycle of these xenobiotics using plant foliage as sampling tools of air contamination (Calamari et al., 1991). Vegetable biomass plays an important role in the global cycling of lipophilic persistent organic pollutants because of its large amount of organic matter capable of binding and accumulating pollutants (Wania and McLachlan, 2001). Atmospheric uptake of POPs is considered the main accumulation pathway (McLachlan and Horstmann, 1998).

Multimedia environmental models were developed in an attempt to describe the environmental fate of POPs between different compartments at regional scale. Recently, the importance of vegetation compartments, particularly in the case of coniferous and deciduous forests (Calamari et al., 1991; McLachlan, 1999; Wania and McLachlan, 2001), in multimedia mass balance models was shown to be necessary to accurately predict the fate of chemicals in the air-soil transfer. Spatially distributed multimedia models, which can calculate the fate of POPs in entire regions, are strongly limited by the availability of data representing the distribution, structure and function of different vegetation species, in terms of biomass and its spatial and temporal variability. A better description of the characteristics of the vegetal biomass on a territory could accurately predict the fate of POPs.

Radiometric measurements collected from Earth observation sensors onboard of aerial and satellite platforms offer the opportunity to describe the terrestrial biosphere at different spatial scales. Remote sensing techniques were successfully used to characterize the state and properties of vegetation types. Satellite remote sensing nowadays furnishes basic data for forest inventories providing information about structure and typology of forest over wide areas. Aerial surveys with hyperspectral images can be used to produce cover mapping that gives a detailed spatial distribution of natural forest species in complex and heterogeneous areas (Martin et al., 1998; Thomas et al., 2002). Moreover a quantitative estimation of vegetation biophysical properties, such as the Leaf Area Index (LAI) and Fractional cover $(\mathrm{Fc})$, can be retrieved from remote sensing data by statistical relationships with ground measurements (Chen et al., 1997; Turner et al., 1999; Boschetti et al., 2002). LAI is one of the most important bio-physical parameters because it quantifies the amount of foliage area per unit of ground surface area. Being a measure of the surface that interacts with light, LAI is therefore related to bio-physical vegetation activities, such as photosynthesis, respiration, transpiration. Foliage biomass, due to the lipid content of leaves, governs assimilation processes and represents a necessary input to the multimedia models able to describe the fate of POPs (Cousins and Mackay, 2001).

This work, conducted in the frame of the DARFEM (DAIS and ROSIS for Forest Ecosystem Monitoring) experiment (Brivio et al., 2001), aims at a better understanding of the capabilities of hyperspectral airborne data in the determination of the vegetation parameters used in POPs multimedia models. In particular hyperspectral images were used to map the natural species distribution and to retrieve leaf area index and foliage biomass.

\section{Study area}

The study area belongs to Ticino River regional park and is located South West of Milan, Italy (fig. 1). In a few kilometres the site encompasses a range of land cover types typical of Northern Italy, including intensive poplar plantations, natural broad-leaved forest, water courses, rice fields, grassland and transitional woodland/shrub representing forest regeneration. Two sub-sites in this landscape received the focus of the investigation, the natural forest and 

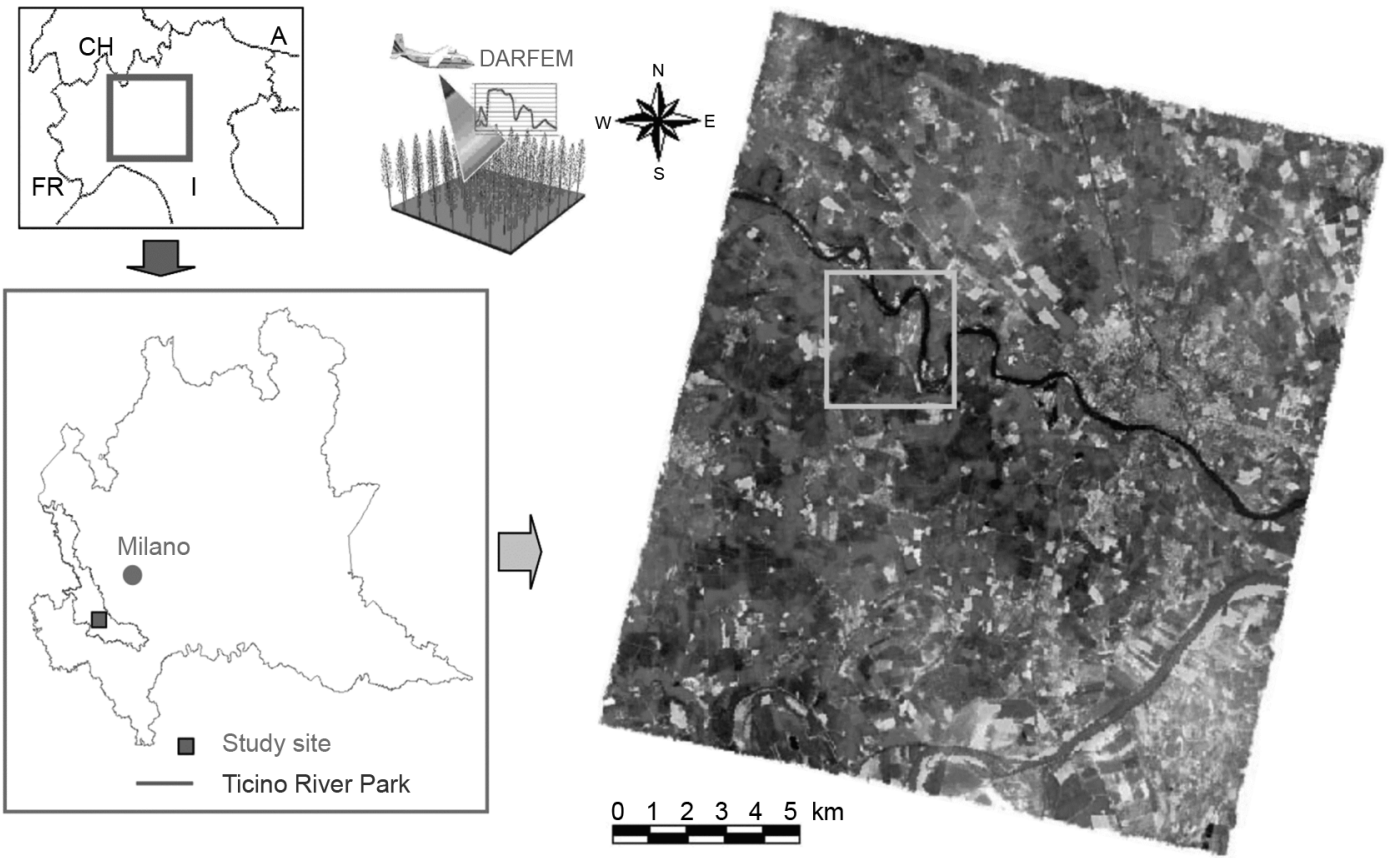

Fig. 1. Location of study site within the Ticino River regional park; Landsat-7 ETM+ image of the target area with the Ticino water course acquired 21/06/2003.

the poplar plantation, to evaluate the role on POPs fate of a natural area and of an arboreal agro-ecosystem. The broadleaf forest in this region is in fact a unique ecosystem, almost completely undisturbed, and it represents the natural ecological climax for the Po River plain. The poplar plantation (Kyoto forest or fast growing forest) is an intensive crop which is a permanent investigation site of CARBOEUROFLUX network, managed by the Institute for Environment and Sustainability of the Joint Research Centre (Ispra, Italy).

\section{Materials}

\subsection{Remote sensing data}

DARFEM experiment, developed in the framework of EU-funded HySens project coordinated by DLR (German Aerospace Agency), was specifically designed to provide a better understanding of the capability of airborne hyperspectral observations in the retrieval of physiologically relevant vegetation parameters.

Aerial surveys were operated from 10.30 to 11 am on 20th June 2001 using two spectrometers of DLR: DAIS 7915 (Digital Airborne Imaging Spectrometer) and ROSIS (Reflective Optics System Imaging Spectrometer). The next day the area was also surveyed by MIVIS (Multispectral Infrared and Visible Imaging Spectrometer) of CNR LARA project, simultaneously with Landsat 7 ETM+ passage.

DAIS 7915 is a whisk-broom scanner operating in 79 spectral channels in the range from visible to thermal infrared wavelengths with 512 image pixels per scan line.

ROSIS is a push-broom imaging spectrometer whose spectral range is limited to the visible and near infrared wavelengths (430-850 $\mathrm{nm}$ ). Table I lists the main specifications of the two hyperspectral systems compared with the MIVIS sensor. 
Table I. Spectral and geometric characteristics of different hyperspectral sensors. Flight height was $1800 \mathrm{~m}$ determining a pixel size for DAIS and MIVIS of about $2.5 \mathrm{~m}$ and for ROSIS of $1 \mathrm{~m}$.

\begin{tabular}{|c|c|c|c|c|c|c|c|}
\hline & Sensors & Scanner type & FoV & IFoV [mrad] & Spectrometers & Channels \# & Spectral range $[\mathrm{nm}]$ \\
\hline \multirow[t]{5}{*}{ DLR } & \multirow[t]{5}{*}{ DAIS } & \multirow[t]{5}{*}{ Whisk broom } & \multirow[t]{5}{*}{ $\pm 26^{\circ}$} & \multirow[t]{5}{*}{3.3} & 1 & 32 & $400-1000$ \\
\hline & & & & & 2 & 8 & $1500-1800$ \\
\hline & & & & & 3 & 32 & $2000-2500$ \\
\hline & & & & & & 1 & $3000-5000$ \\
\hline & & & & & 4 & 6 & $8000-12600$ \\
\hline DLR & ROSIS & Push broom & $\pm 8^{\circ}$ & 0.56 & 1 & 115 & $430-860$ \\
\hline \multirow[t]{4}{*}{ CNR } & \multirow[t]{4}{*}{ MIVIS } & \multirow[t]{4}{*}{ Whisk broom } & \multirow[t]{4}{*}{ $\pm 35^{\circ}$} & \multirow[t]{4}{*}{2} & 1 & 20 & $430-830$ \\
\hline & & & & & 2 & 8 & $1150-1550$ \\
\hline & & & & & 3 & 64 & $2000-2500$ \\
\hline & & & & & 4 & 10 & $8200-12700$ \\
\hline
\end{tabular}

Since the reflectance distribution of vegetation is strongly anisotropic, the flight lines were designed with the aim of maximizing the number of DAIS directional observations in the principal solar plane of the area (Brivio et al., 2001). Multi-angular observations were used, in the framework of DARFEM project, for the inversion of radiative transfer models (Meroni et al., 2002).

For the scope of this work, i.e. species distribution from classification and LAI estimation from semi-empirical modeling, only data acquired in the solar plane, where the Bi-directional Reflectance Distribution Function (BRDF) effects are minimized, were utilized.

During the aerial survey synchronous radiometric ground measurements were acquired for different purposes. FieldSpec FR spectroradiometer, operating in a wavelength range from 350 to $2500 \mathrm{~nm}$, was used to collect spectra from different natural surfaces and over two different artificial targets to evaluate the subsequent procedure of radiometric correction. The aerosol optical thickness of the atmosphere was estimated by means of the Langley method using data collected by the MS-120 Eko Sun-photometer (spectral peak at $368 \mathrm{~nm}, 500 \mathrm{~nm}, 678 \mathrm{~nm}$ and $778 \mathrm{~nm}$ ). Aerosol content at $550 \mathrm{~nm}$ is in fact the necessary input to the radiative transfer codes (i.e. 6S, Lowtran, ATCOR4) for the atmospheric correction of airborne hyperspectral data.

The atmospheric correction was made by DLR using ATCOR4 considering the effects of angular dependence of the atmospheric radiance and transmittance, and the aerosol contributions from values estimated through ground photometric measurements collected during the overpass.

\subsection{Field campaign}

The field campaign of this study was addressed to forestry species identification and LAI measurements. The species distribution can be mapped through automatic classifications, but those methods need to be trained with spectral examples of the species present in the images. LAI can be spatially estimated using semi-empirical regression model between ground measurements and spectral radiometric observations (Chen and Chilar, 1996; Eklundh et al., 2001).

Beside the poplar plantation, characterized by hybrid poplar (Populus Euroamericano), the main species identified in the natural forest area include black poplar (Populus nigra), English oak (Quercus robur), black locust (Robinia pseudoacacia) and white willow (Salix alba). Several sample areas with homogeneous presence of natural species were identified on the field with the aid of forest specialists and geocoded using a GPS Garmin III+ in order to recognize those areas on the images.

LAI measurements were obtained with the LAI-2000 Plant Canopy Analyser (PCA) in the same week as the aerial survey for the poplar plantation, and in the following weeks for the natural forest areas. The LAI-2000 PCA instru- 
ment correlates the total leaf area with the probability of light penetration, canopy gap fraction, through the canopy (LI-COR, Inc., Lincoln, Nebrasca, U.S.A.). LAI-2000 PCA measures light intensities, in spectral range of blue, in five concentric fields of views at zenith angle of $7^{\circ}, 23^{\circ}$, $38^{\circ}, 53^{\circ}$ and $68^{\circ}$ corresponding to 5 different sensors (Welles and Norman, 1991).

The measurements acquired by the LAI2000 instruments represent an effective Leaf Area Index (LAIe) rather than the LAI of the green part (Chen and Chilar, 1996). These measurements in fact do not take into consideration the clumping effects present in vegetation. In natural conditions this effect can be neglected due to the complexity of the forest and the random distribution of leaves. Moreover, the LAIe has to be considered a Plant Area Index (PAI) because all the non-leaf tissues (stems, branches etc.) that intercept light contribute to the gap fraction measurements. This effect was not measured because it can be considered negligible in our conditions. The measurements were conducted to minimise errors due to different illumination conditions, boundary effects and the non random distribution of the poplar plantation (Colombo et al., 2002).

\section{Data analysis}

Measurements collected at every field site include spectral signatures of the surface, overstory LAI measurements, digital photography of the understory (nadir taken) and overstory (zenith taken), species typology and in some cases also leaf chlorophyll and water content. Each site was geo-located using a GPS system and all data collected were recorded and managed in a dedicated GIS, able to integrate these data with ancillary topographic and thematic maps of the study area. These data were then overlapped to the remote sensing images in order to study and select the spectral responses of the relative pixels.

\subsection{Classification}

The classification was conducted on the DAIS data due to their spectral range covering short-wave infrared (SWIR) region. In fact, SWIR bands are considered very important for vegetation analysis (Martin et al., 1998; Fuentes et al., 2000). An analysis of the spectral quality and importance of the DAIS channels was conducted for the features selection before the classification. Spectral channels between \#41 to \#43 and \#61 to \#68 were rejected because of the low $\mathrm{S} / \mathrm{N}$ ratio.

\subsection{Training selection and mapping algorithm}

The spectral examples for the different classes were chosen on the images overlapping the GPS position of the field survey. The pixels of training were selected by visual interpretation of different RGB composition and by the analysis
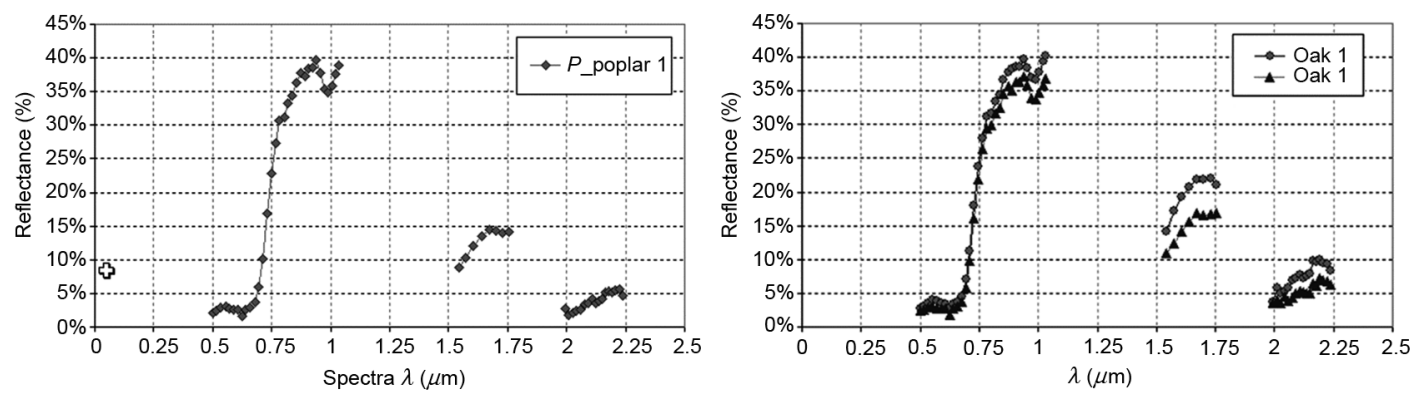

Fig. 2. Examples of spectral endmembers selected by correlation analysis conducted on 20 DAIS spectra. Image location was defined with the help of GPS measurements and visual interpretation of false colour imagery. 
of NDVI (Normalized Different Vegetation Index) maps in order to identify the brightest pixel representing dense crowns: these pixels guarantee that shadows and canopy opening or other species influence do not affect the radiometric measurement. As a result of a correlation analysis conducted over 20 spectra selected from the GPS positions, some classes, such as the English oak, present for the classification more than one endmember spectra representing natural variability due to different ecological conditions (fig. 2). Spectral bands selected were processed through Spectral Angle Mapper (SAM) algorithm using a training data set including all the endmembers for the different species. SAM implemented in ENVI software is a physicallybased spectral classification that uses an $n$-dimensional angle to match pixels to reference spectra extracted from the training data set (Kruse et al., 1993). The algorithm determines the spectral similarity between two spectra by calculating the angle between the spectra, treating them as vectors in a space with dimensions equal to the number of bands. SAM algorithm distributes the image pixels in the appropriate class depending on the reference spectrum that presents the minimum angle. The procedure also requires a specified maximum acceptable angle in radians between spectral vectors; definition of threshold for the not classified pixels is always a critical step. Threshold value was fixed at 0.04 radians for this study.

\subsection{LAI estimation}

Leaf area index for an extended area can be determined through the definition of a semi-empirical regression model between ground measurements and spectral Vegetation Indices (VIs), such as band ratios or normalized bands difference, computed from remotely sensed images (Chen and Chilar, 1996; Eklundh et al., 2001). Semi-empirical relationships can be found in different mathematical forms depending on vegetation type and forest structure (Chen et al., 1997; Turner et al., 1999). The relationships are also strongly affected by the understory composition and canopy closure (Spanner et al., 1990; Brown et al., 2000) and by the accuracy of ground-

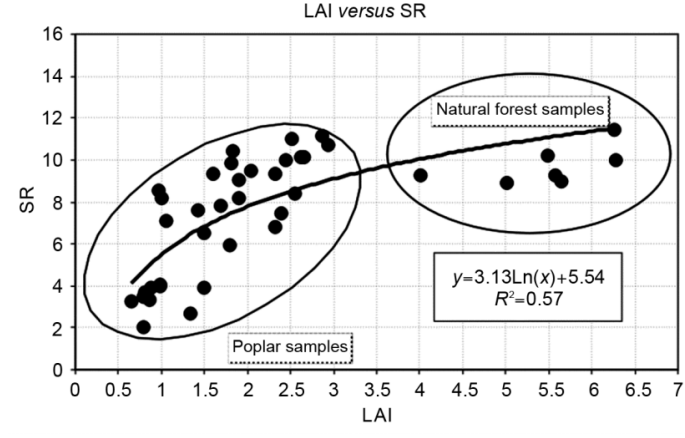

Fig. 3. Logarithmic regressive relationship between LAI and SR. Leaf area index values appear to be distributed in two different populations. The mature natural forest express the highest values of LAI.

based measurements (Chen and Chilar, 1996). In order to find the best semi-empirical relationship between VIs image derived and LAI field measurements, a set of $4 \times 4$ pixels windows were extracted from the georeferenced DAIS image. The windows were selected on the basis of GPS measurements position and on the analysis of NDVI image: their homogeneity was statistically guaranteed by a coefficient of variation for each band generally smaller than $5 \%$.

The best model obtained by regressive analysis between values of LAI-2000 measurements and values of Simple Ratio (SR) is logarithmic type (fig. 3) showing a correlation coefficient of 0.57

$$
S R=3.13 \ln (\mathrm{LAI})+5.54 .
$$

Therefore the mathematical expression for determination of LAI is

$$
\mathrm{LAI}=\mathrm{e}^{\frac{(\mathrm{SR}-5.54)}{3.13}} .
$$

The SR index is calculated as the ratio between near infrared (central wavelength $802 \mathrm{~nm}$ ) and red (central wavelength $659 \mathrm{~nm}$ ) corresponding to DAIS channels \#18 and \#10. The relation was checked with Fisher test for its statistical significance; the $F$ value expresses by the relation $(F=49.57)$ largely overpass the $F$ critical value both for $95 \%(\mathrm{Fc}=4.10)$ and $99 \%(\mathrm{Fc}=$ $=7.35$ ) level of confidence. 


\section{Analysis of the results}

\subsection{Map of species distribution}

The map of species distribution obtained from the automatic classification of DAIS hyper- spectral imagery using SAM algorithm is presented in fig. 4a. Visual inspection of this map indicates that these data, thanks to high spectral and spatial resolution, seem to be suitable to perform a detailed identification of different forest species in a complex ecosystem. The large homogeneous
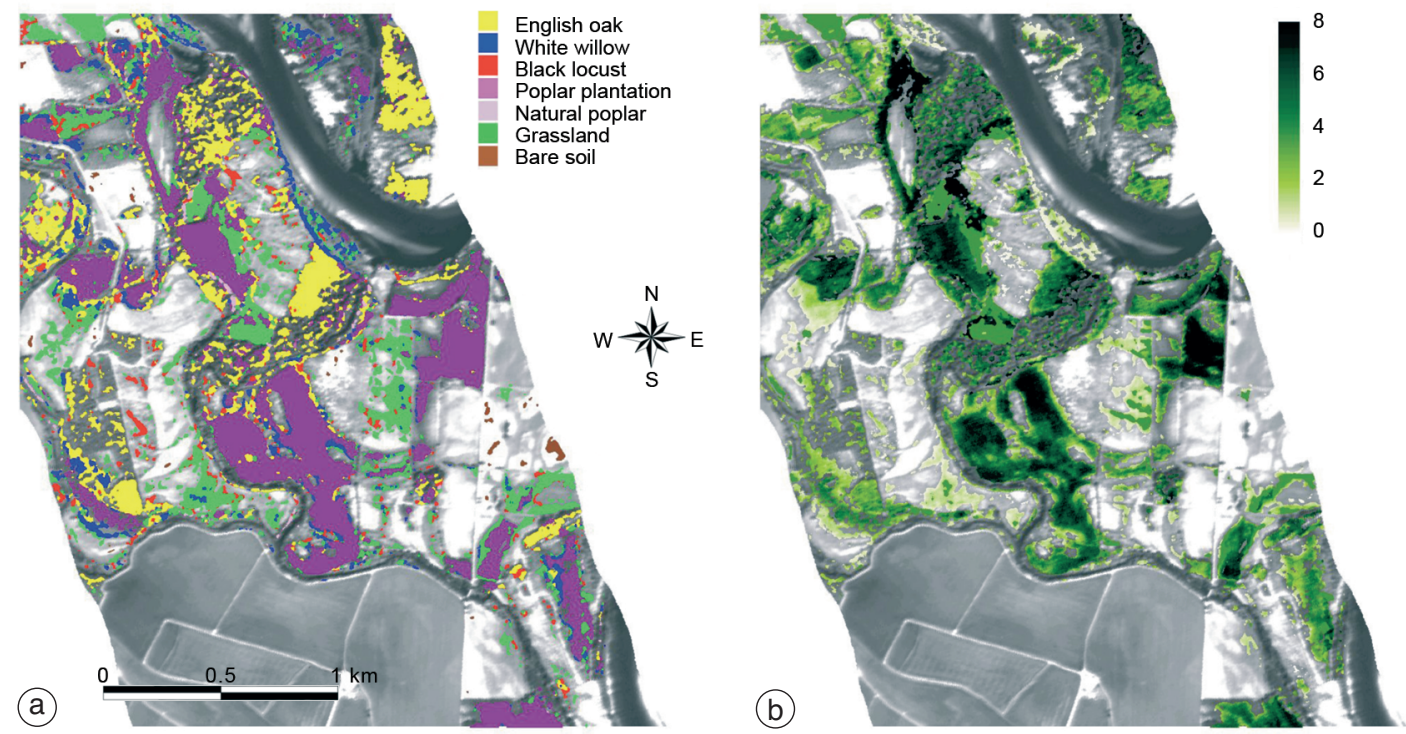

Fig. 4a,b. Remote sensing results: a) map of the forest species distribution obtained from automatic classification of DAIS hyperspectral images (grey tones correspond to not relevant areas, such as bare soil, water and rice fields); b) map of Leaf Area Index (LAI) for the natural forest and poplar plantation. LAI values are computed on the classes identified in the forest species map.

Table II. Confusion matrix computed for the evaluation of classification accuracy. PA refers to producer accuracy and UA to user accuracy.

\begin{tabular}{lcccccccc|cc}
\hline \hline Classes & $\begin{array}{l}\text { Natural } \\
\text { poplars }\end{array}$ & Oak & Willow & $\begin{array}{c}\text { False- } \\
\text { acacia }\end{array}$ & $\begin{array}{c}\text { Poplar } \\
\text { plantation }\end{array}$ & $\begin{array}{c}\text { Bare } \\
\text { soil }\end{array}$ & Grassland & Total & PA (\%) UA(\%) \\
\hline Unclassified & 5 & 7 & 12 & 5 & 5 & 35 & 10 & 79 & & \\
Natural poplars & $\mathbf{1 6}$ & 5 & 0 & 1 & 0 & 0 & 0 & 22 & 57.14 & 72.73 \\
English oak & 7 & $\mathbf{2 2}$ & 0 & 7 & 0 & 0 & 1 & 37 & 55.00 & 59.46 \\
White willow & 0 & 0 & $\mathbf{5 5}$ & 0 & 0 & 0 & 3 & 58 & 76.39 & 94.83 \\
Black locust & 0 & 3 & 0 & $\mathbf{2 0}$ & 0 & 0 & 1 & 24 & 54.05 & 83.33 \\
Poplar plantation & 0 & 2 & 0 & 1 & $\mathbf{1 3 2}$ & 0 & 2 & 137 & 96.35 & 96.35 \\
Bare soil & 0 & 0 & 0 & 0 & 0 & $\mathbf{2 8}$ & 0 & 28 & 44.44 & 100.00 \\
Grassland & 0 & 1 & 5 & 3 & 0 & 0 & $\mathbf{1 5 1}$ & 160 & 89.88 & 94.38 \\
Total & 28 & 40 & 72 & 37 & 137 & 63 & 168 & $\mathbf{5 3 0}$ & & \\
\hline
\end{tabular}


purple areas represent the poplar plantation, that occupies most of the study zone. The white willow trees, marked in blue, are found in the riparian zone, whereas the English oak, spotted yellow area, is classified mainly in the natural area.

The agreement between reference data and classification results was analyzed by means of the confusion matrix to assess the accuracy of the automatic procedure (table II). Although the number of samples for the accuracy analysis is small, due to the difficulty of the selection of test pixels in the mixed forest, the sample size used guarantees a level of confidence higher than $85 \%$ for all classes (Van Genderen et al., 1978). The overall accuracy achieved is $78 \%$ with a Kappa coefficient of 0.73 .

The confusion matrix also computes class Producer (PA) and User Accuracies (UA). These statistical indices show that some species can be identified and mapped with a higher accuracy (poplar plantation PA $=\mathrm{UA}=96 \%$, willow $\mathrm{PA}=76 \%$ and $\mathrm{UA}=95 \%$ ) than other species such as English oak and black locust, which are more difficult to map. In general, in a complex ecosystem, characterized by a strong heterogeneity, the identification of different species was more complicated. These accuracy results are similar and even better when compared with recently published works (Martin et al., 1998; Thomas et al., 2002). Low accuracy values for soil are due to the inefficiencies in endmembers collection. This class was not involved in this study and was neglected in further analysis.

\subsection{Maps of LAI and foliage biomass}

Statistical stability of the semi-empirical model, derived by regressive analysis between
LAI and SR, was evaluated with the Leave One Out technique. In order to estimate the goodness in prediction of the model, the coefficient of correlation in prediction $Q^{2}$ and Standard Deviation Error in Prediction (SDEP) of the model were calculated for predicted LAI values, excluding the subset of measurements used for model derivation. This analysis showed a value of $Q^{2}=0.51$ and of $\mathrm{SDEP}=1.27$ underlining the possibility of applying the model in prediction. LAI map was then computed only for those pixels belonging to the vegetation classes previously mapped in the study area (fig. 4b). LAI values range from 0.41 to 5.15 , with maximum values occurring in the natural forest for the class of natural poplar.

Multimedia models used to study the fate of POPs and their redistribution in different environmental compartments, from the atmosphere to soil or water via vegetation interface, require foliage biomass information. Foliage Biomass (FB) was estimated with the following model:

$$
\mathrm{FB}_{i}=\mathrm{LAI}_{i} \times \frac{1}{\mathrm{SLA}_{i}} \times\left(\frac{\mathrm{FW}}{\mathrm{DW}}\right)_{i}
$$

where $\mathrm{FB}_{i}$ is the foliage biomass of vegetation class $i\left(\mathrm{~kg} / \mathrm{m}^{2}\right), \mathrm{LAI}_{i}$ is the leaf area index of vegetation class $i, \mathrm{SLA}_{i}$ is the specific leaf area $\left(\mathrm{m}^{2} / \mathrm{kg}\right)$ of vegetation class $i$, and $(\mathrm{FW} / \mathrm{DW})_{i}$ is the relative ratio between fresh and dry biomass weight of vegetation class $i$.

Table III reports the values of SLA as well as the index (FW/DW) used in this work; these parameters depend on the different species and were measured during previous experiments (Marazzato, 2001; Ceriani, 2003). Considering the range of variability of the parameters used in the eq. (5.1), it can be observed that LAI estimations considerably determine the value of

Table III. Specific Leaf Area (SLA) and ratio between fresh and dry weight (FW/DW) values.

\begin{tabular}{cccc}
\hline \hline Species & Latin name & SLA $\left(\mathrm{m}^{2} / \mathrm{kg}\right)$ & FW/DW \\
\hline Black poplar & Populus nigra & 13.60 & 3.25 \\
English oak & Quercus Robur & 14.25 & 2.65 \\
Black locust & Robinia pseudacacia & 11.65 & 3.05 \\
White willow & Salix alba & 11.65 & 3.15 \\
Grassland & Dactylis glomerata & 22.00 & 3.83 \\
\hline
\end{tabular}



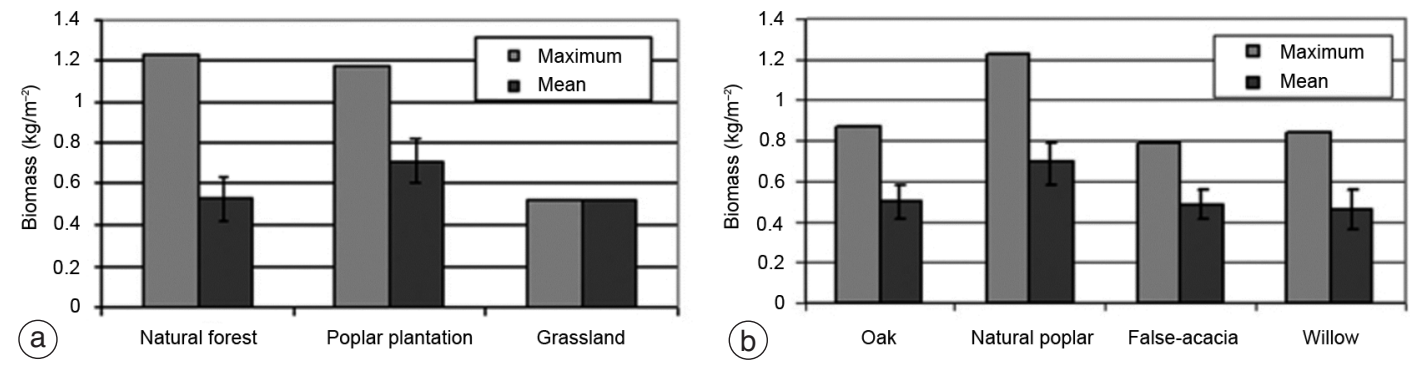

Fig. 5a,b. Mean and maximum biomass values a) for the main vegetation types (natural forest, poplar plantation and grassland) and b) for the different species identified within natural forest.

the FB results: in fact LAI values vary by a factor of around 10 (0.5-6.5) while SLA and ratio FW/DW by a factor of $2(11.65-22.00)$ and 1.5 (2.65-3.83) respectively (table III).

Therefore, it can be inferred that the spatial estimation of FB is strongly affected by the LAI value selected, justifying a spatial determination of this parameter as obtained in this work.

Three main vegetation types considered have different biomass and the maximum is reached by the natural forest (fig. 5a). Field LAI measurements for the grassland type were not available, therefore for this class the biomass values correspond to a mean value found in literature (Allen et al., 1998). The second histogram (fig. $5 b)$ shows the biomass values for the different species identified in the natural forest area, the maximum value is found for natural poplar. The diverse species have a different role in the filter effect and consequently make a specific contribution to the fate of POPs. The possibility of determining vegetation cover, species and LAI, from remote observation allows us to attribute spatial specific biomass values to the studied region, considering that the usual practice is to specify an average biomass value to the entire region which can be highly uncertain given the very subjective expert judgment needed.

\section{Conclusions}

In this research remote sensing techniques were successfully used to characterise the state and properties of vegetation types. The automatic classification of aerial hyperspectral data allowed us to produce species distribution map with a good accuracy. More efforts are needed to define efficient methods of analysis, capable of both fusing multisensor multispectral information and exploiting the spatial relationships of neighbouring pixels in order to extract highly accurate information. Neural network techniques can be suitable to treat this multi-source approach. Moreover, a quantitative estimation of LAI has been achieved from remote sensing data, vegetation index, by statistical relationships with ground measurements. The semi-empirical model defined has a predictive validity but further analyses are required. The definition of specific relationships for the natural area and the poplar plantation should guarantee better results. More field LAI measurements in the natural areas are therefore needed. The biomass map produced by GIS techniques represents a useful input for spatially distributed multimedia models that take into account the role of vegetation type.

The approach of using remote sensing techniques to achieve a detailed analysis of type and status of vegetation type can help to understand the fate of persistent organic pollutants (POPs) in the environment. These data represent significant input for the application of spatially distributed multimedia models that is usually strongly limited by the availability of data representing the structure and function of vegetation. 


\section{Acknowledgements}

This work was supported by the EU-funded project HySens coordinate by DLR (Germany) and by JRC that manages and maintains the instrumentation of the study area. We gratefully acknowledge the Ticino River regional park staff for the necessary local support and Dr. Cerabolini and Dr. Ceriani for their comments and suggestions and for making SLA data available.

\section{REFERENCES}

Allen, R.G., L.S. Pereira, D. Raes and M. Smith (1998): Crop evapotraspiration, FAO Irrigation and Drainage Paper 56.

Boschetti, M., R. Colombo, M. Meroni, C. Panigada, P.A. BRIVIO and J. R. MiLleR (2002): Use of semi-empirical and radiation transfer model to estimate biophyisical parameters in a sparse canopy forest, in Remote Sensing for Agriculture, Ecosystems and Hydrology, edited by M. Owe, G. D'Urso and L. Toulios, SPIE Proc., 4879, 133-144.

Brivio, P.A., M. MERoni and C. GiARdino (2001): Monitoring forest ecosystems using hyperspectral and directional observations, in ESA Workshop on SPECTRA, 12-13 June 2001, Nordwijk (The Netherlands), ESA SP-474.

Brown, L., J.M. Chen, S.G. LeblanC and J. Cihlar (2000): A shortwave infrared modification to the simple ratio for LAI retrieval in Boreal Forests: an image and model analysis, Remote Sensing Environ., 71, 16-25.

Calamari, D., E. Bacci, S. Focardi, C. GagGi, M. MorosiNI and M. VIGHI (1991): Role of plant biomass in the global environmental partitioning of chlorinated hydrocarbons, Environ. Sci. Technol., 25 (8), 1489-1495.

CERIANI, R.M. (2003): Caratteristiche ecologiche, morfofunzionali e riproduttive di specie vegetali delle praterie prealpine lombarde, Tesi di Dottorato (Dottorato di ricerca in «Analisi, protezione e gestione della biodiversità» XV ciclo, Università degli Studi dell'Insubria).

Chen, J.M. and J. CiHlaR (1996): Retrieving leaf area index of boreal conifer forests using Landsat TM images, Remote Sensing Environ., 55 (2), 153-162.

Chen, J.M, P.M. Rich, S.T. Gower, J.M. Norman and S. PlumMER (1997): Leaf area Index of Boreal Forests: theory, techniques, and measurements, J. Geophys. Res., 102, 29429-29443.

Colombo, R., M. Boschetti, C. Giardino, M. Meroni, C. Panigada, L. Busetto, P.A. Brivio, C.M. Marino and G.M. SEUFERT (2002): Osservazioni remote iperspettrali e multiangolari per la stima dei parametri biofisici della vegetazione, Parte I. Progettazione dell'esperimento e analisi dei dati, Riv. Ital. Telerilevamento, 24, 5-13.

Cousins, I.T. and D. MACKAY (2001): Strategies for including vegetation compartments in multimedia models, Chemosphere, 44, 643-654.
EKLUndH, L., L. HARRIE and A. KUUSK (2001): Investigating relationships between Landsat ETM+ sensor data and leaf area index in a boreal conifer forest, Remote Sensing Environ., 78 (3), 239-251.

Fuentes, D., J. Gamon, H. Qiu, D. Sims and D. Roberts (2000): Mapping vegetation cover types in the canadian boreal forest using pigment and water absorption features derived from AVIRIS, in Proceedings of the Ninth JPL Airborne Earth Science Workshop NASA.

Kruse, F.A., A.B. Lefkoff, J.B. BoArdman, K.B. HeIdEBRECHT, A.T. Shapiro, P.J. BARloOn and A.F.H. GoETZ (1993): The Spectral Image Processing System (SIPS) Interactive visualization and analysis of imaging spectrometer data, Remote Sensing Environ., 44, 145-163.

Mackay, D., A. Di Guardo, S. Paterson, G. Kicsi and C. E. CowAN (1996): Assessing the fate of new and existing chemicals: a five-stage process, Environ. Toxicol. Chem., 15 (9), 1618-1626.

MARAZZATo, M. (2001): Variazioni stagionali di alcuni parametri fogliari nelle principali specie legnose delle vegetazioni delle Alpi, Tesi di Laurea (Facoltà di Scienze Biologiche, Università degli Studi dell'Insubria).

Martin, M.E., S.D. Newman, J.D. Aber and R.G. CongalTON (1998): Determining forest species composition using high spectral resolution remote sensing data, $R e$ mote Sensing Environ., 65, 249-254.

MCLaChlan, M.S. (1999): Framework for the interpretation of measurements of SOCs in plants, Environ. Sci. Technol., 33, 1799-1804.

MCLAChlan, M.S. and M. Horstmann (1998): Forests as filters of airborne organic pollutants; a model, Environ. Sci. Technol., 32, 413-420.

Meroni, M., R. Colombo, M. Boschetti, C. Panigada, M. Rossini, P.A. BRIVIO and J.R. Miller (2002): LAI retrieval from multi-angle and hyperspectral observations in an intensively-managed poplar plantation, in 1st Int. Symp. "Recent Advances in Quantitative Remote Sensing», Valencia (Spain), 900-903.

Spanner, L., L. Pierce, D.L Peterson and S.W. Running (1990): Remote sensing of temperate coniferous forest leaf area index. the influence of canopy closure, understorey vegetation and background reflectance, Int. J. Remote Sensing, 11, 95-111.

Thomas, V., P. Treitz, D. Jelinski, J.R. Miller, P. Lafleur and J.H. MCCAUGHEY (2002): Image classification of a northern peatland complex using spectral and plant community data, Remote Sensing Environ., 84, 83-99.

Turner, D.P., W.B. Cohen, R.E. Kennedy, K.S. FAssnacht and J.M. BRIGGS (1999): Relationship between Leaf Area Index and Landsat TM Spectral Vegetation Indices across three temperate zone sites, Remote Sensing Environ., 70, 52-68.

VAN GENDEREN, J.L., B.F. LOCK and P.A. VASS (1978): Remote Sensing: Statistical testing of thematic map accuracy, Remote Sensing Environ., 7, 3-14.

WANIA, F. and M.S. MCLACHLAN (2001): Estimating the influence of forests on the overall fate of semivolatile organic compounds using a multimedia fate model, Environ. Sci. Technol., 35, 582-590.

WELLES, J.M. and J.M. NoRMAN (1991): Instrument for Indirect Measurements of Canopy Architecture, Agron. J., 83 (5), 818-825. 